Ann. Human Genet (Lond.) 25:111, 1961

15. Penrose, L. S.: Mongolism, Brit. M. Bull. $17: 184,1961$.

16. Penrose, L. S., and Delhanty, J. D. A.: Familial Langdon Down anomaly with chromosomal fusion, Ann. Human Genet. (Lond.) 25:243, 1961 .

17. Zellweger, H., and Mikamo, K.: Autosomal cytogenetics, Helvet. paediat. acta 16:670, 1961.

18. Silverman, J. J., Berman, H. B., and Szancer, H.: A study of the parentage in Mongolism with congenital heart disease, Circulation 12:775, 1955.

19. Patau, K., Smith, D. W., Therman, E., Inhorn, S. L., and Wagner, H. P.: Multiple congenital anomaly caused by an extra chromosome, Lancet $1: 790,1960$.

20. Ellis, J. R., and Marwood, J. C.: Autosomal trisomy syndromes, Lancet $2: 263,1961$.

21. Edwards, J. H., Harnden, D. G., Cameron, A. H., Crosse, V. M., and Wolfe, O. H.: A new trisomic syndrome, Lancet 1:787, 1960.

22. Smith, D. S., Patau, K., Therman, E., and Inhorn, S. L.: A new autosomal trisomy syndrome, J. Pediat. 57:338, 1960.

23. Uchida, I. A., and Bowman, J. M.: XXX 18Trisomy, Lancet 2:1094, 1961.

24. Böök, J. A., Santesson, B., and Zetterqvist, P.: Association between congenital heart malformation and chromosomal variations, Acta paediat. $\mathbf{5 0 : 2 1 7 , 1 9 6 1 . ~}$

\title{
Regulation of blood pressure: A cybernetic mechanism residing in the kidney?
}

Recent evidence that two separate and opposing secretions from the pancreas serve to regulate blood sugar suggests that other important constants of the "milieu interieur" may be subject to a double control on the part of a single organ. The endocrine secretions of the kidney may well provide a second example, in this case as a regulating mechanism for control of the blood pressure.

There is ample evidence that under circumstances of reduced perfusion pressure the kidney secretes a pressor substance which serves to elevate systemic arterial pressure. Although the nature of the secretion has not been clearly identified, it would seem to be renin, which originates from the juxta-glomerular cells and, through direct and indirect mechanisms, releases a variety of less complex molecules, such as angiotensin and aldosterone, substances which serve to elevate the blood pressure. Studies of shock and of the response of blood pressure to nephrectomy or to renal vascular surgery leave little doubt that the kidney does secrete acutely and chronically a humoral pressor substance, although detection of it in the blood by our present methods is extremely difficult.

Fvidence for a contrarily acting mechanism which originates in the kidney is also accumulating. The inhibiting effect of normal kidney tissue upon the development of renal "ischemic" hypertension is well recognized. Muirhead has located the cells which perform this function in the renal medulla, and he and Grollman have described an extract which, under special circumstances, has an antipressor effect. Milliez has recently isolated a substance from rabbit kidney medulla which has a prolonged antihypertensive action in the renal hypertensive rabbit. Furthermore, kidney transplants in man and animals rapidly normalize the blood pressure in cases of renal hypertension but do not produce hypotension.
The kidney seems to stop releasing its antihypertensive secretion when the blood pressure reaches normal: Tobian has demonstrated in the rat that the depressor action of the normal kidney appears only when this organ is under increased perfusion pressure, whereas studies in our laboratory indicate that the depressor effect of kidney transplants, which is easy to demonstrate when the blood pressure is elevated by figure-of-eight ligation of the opposite kidney, does not lower the blood pressure of a normotensive animal.

These observations corroborate the intimate and reciprocal relationship between normal and "ischemic" kidneys which was described many years ago by Friedman and collaborators, further examined in the elegant experiments of Wilson and Byron on the "touched" and the "untouched" kidney, and recently extended by Gross, who has shown that the renin content of the contralateral kidney is reduced in the case of unilateral renal hypertension. This reciprocal relationship has been demonstrated in many other contexts since it was first described by Goldblatt in his classic experiments. A review of the literature and a presentation of some of the latest experiments in this field are referred to in a recent symposium, reprints of which are available on request to interested investigators.*

If indeed the kidney will some day prove to be the source of two oppositely acting secretions, both concerned with regulation of the blood pressure, of what importance would this conclusion be to the clinician and to the investigator? In the first place, such a finding would serve to reconcile the renal and

*Symposium on Experimental Renal Hypertension, University of Michigan Medical Bulletin 27:175, 1961. Reprints may be obtained by writing to Dr. Walter Freyburger, The Upjohn Company, Kalamazoo, Mich. 
renoprival explanations for the etiology of hypertension. In the second place, it might encourage investigators to look for the pathogenesis of essential hypertension in terms of a deficiency of the appropriate renal response to elevated blood pressure. In the third place, more widespread recognition of the antihypertensive role of the normal kidney should cause surgeons to hesitate to remove "ischemic" kidneys when revascularization is at all possible in the treatment of renal vascular hypertension. Finally, studies to isolate a hormone from the kidney which might regulate the blood pressure down to but not below the normal value would seem to offer more therapeutic advantages in the treatment of hypertension than the further development of nonspecific depressor substances. Discovery of such a substance in normal kidney tissue would introduce a new era in the treatment of hypertension comparable to that which followed the discovery of liver extract for the treatment of pernicious anemia. The significant investigations now proceeding in this direction deserve more attention than has so far been accorded to them in laboratories devoted to research in the problems of experimental and clinical hypertension.

Sibley W. Hoobler, M.D.
Professor of Internal Medicine
Hypertension Lnit
Department of Internal Medicine
Lniversity of Michigan Medical School
Ann Arbor, Mich.

Sibley W. Hoobler, M.D. Internal Medicine igan Medical School Ann Arbor, Mich.

\section{The use of steroids in pericarditis}

Pericarditis tends to be a recurrent disease, whether due to viral or bacterial infections, surgical incision of the pericardium, trauma, actinomycosis, or after myocardial infarction. ${ }^{1}$ Recurrences have been reported in as high as 63 per cent of the patients after mitral commissurotony, but rates of 30 to 40 per cent have been more common. ${ }^{2}$ Recurrences have been noted in 18 to 36 per cent of the patients after so-called idiopathic pericarditis..$^{3,4}$ In 100 patients who underwent open-heart operation for congenital defects, 30 per cent developed pericarditis after the operation. ${ }^{5}$

The predominant symptom is distressing pericardial pain, although pleuritis and pneumonitis may also occur. Rarely, the disability from recurrent symptoms has been so great that total pericardiectomy has been necessary for the patient to obtain relief. ${ }^{6,7}$ Stervids have been of particular value in relieving pain. They may be effective at times when opiates are ineffective. Furthermore, they may lessen the dyspnea due to splinting of the chest, without the impairment of ventilation experienced with opiates. The antipyretic effect is beneficial but of secondary importance, except in the rare individual with high fever. In the critically ill child with acute rheumatic or other type of pericarditis, the response within 24 hours may be dramatic. The subsidence of tachypnea with slowing of the pulse rate, the disappearance of an anxious expression, improved appetite, and sense of well-being may be noteworthy.

The impression has been gained that the suppression of inflammation with lessened formation of pericardial fluid may decrease the likelihood of pericardial tamponade. Often the elevated venous pressure may decrease within several days. At the present time there are no data to indicate that the course of a given attack of pericarditis is shortened, and premature withdrawal of steroids often results in the "rebound phenomenon"' with return of pain and fever.
Steroids should be reserved for those who do not respond to salicylates, and those who are severely ill. They should not be used in those in whom tuberculous pericarditis is suspected. The fear that virus infection might be disseminated under steroid therapy has not been borne out.

Prednisone in doses of 40 to $60 \mathrm{mg}$. daily is usually effective and should be gradually reduced by trial and error over a period of 2 to 3 weeks. If symptoms return with decrease in dosage, the amount should again be increased. The administration of gradually increased doses of aspirin during the period of withdrawal may lessen the likelihood of rebound and shorten the course of therapy.

Bruce Logue, M.D. Frank Tutunji, M.D. Department of Internal Medicine Emory University Clinio Allanta, Ga.

\section{REFERENCES}

1. Dressler, W.: Postmyocardial infarction syndrome-report of 44 cases, A.M.A. Arch. Int. Med. 103:28, 1959 .

2. Dresdale, D. T., Ripstein, C. B., Guzman, S. V., and Greene, M. A.: Postcardiotomy syndrome in patients with rheumatic heart disease; cortisone as a prophylactic and therapeutic agent, Am. J. Med. 21:57, 1956.

3. Carmichael, D. B., Sprague, H. B., Wyman, S. M., and Bland, E. F.: Acute nonspecific pericarditis, clinical laboratory and follow-up consideration, Circulation 3:321, 1951.

4. Scherl, N. D.: Acute nonspecific pericarditis. A survey of the literature and a study of 30 additional cases, J. Mt. Sinai Hosp. 23:393, 1956.

5. Engle, M. A., and Ito, T.: The postpericardiot. omy syndrome, Am. J. Cardiol. 7:73, 1961. 